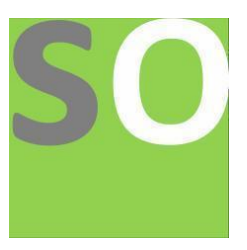

Article title: Characterizing Proficient Teachers as Teacher-Leaders in a Public Secondary School of Leyte Division Authors: Alvin Jhon Manito[1]

Affiliations: Manlilisid National High School, Javier, Leyte, Philippines[1]

Orcid ids: 0000-0001-9894-420X[1]

Contact e-mail: alvinjhonmanito@gmail.com

License information: This work has been published open access under Creative Commons Attribution License $\mathrm{http}: / / c r e a t i v e c o m m o n s . o r g / l i c e n s e s / b y / 4.0 /$, which permits unrestricted use, distribution, and reproduction in any medium, provided the original work is properly cited. Conditions, terms of use and publishing policy can be found at https://www.scienceopen.com/.

Preprint statement: This article is a preprint and has not been peer-reviewed, under consideration and submitted to ScienceOpen Preprints for open peer review.

DOI: 10.14293/S2199-1006.1.SOR-.PPPQQKT.v1

Preprint first posted online: 29 July 2021

Keywords: proficient teacher, teacher-leader, case study, public secondary school, mixed method paradigm 


\title{
CHARACTERIZING PROFICIENT TEACHERS AS TEACHER-LEADERS IN A PUBLIC SECONDARY SCHOOL OF LEYTE DIVISION
}

\author{
Alvin Jhon C. Manito \\ Faculty, Manlilisid National High School, Javier, Leyte, Philippines \\ alvinjhonmanito@gmail.com
}

\begin{abstract}
This case study determines the ability of the classroom teachers of becoming teacher-leaders in school reform in the absence of highly proficient teachers and department heads in the institution. This study aimed to explore and characterize proficient teachers as teacher-leaders at Manlilisid National High School, Javier II District, Leyte Division. This study used mixed method investigative paradigm as its research design. Quantitatively, data were gathered using the Teacher Leadership Self-Assessment (TLSA) by Katzenmeyer and Katzenmeyer (2004). It was randomly distributed to thirteen proficient teachers. Qualitatively, a semi-structured interview was done to three proficient teachers who got highest ratings in the survey. The respondents granted permission to the researcher to use the data obtained. Data were then analyzed using descriptive statistics and thematic analysis. Upon the analysis, the characteristics of the proficient teachers as teacher-leaders are evident in self-awareness, diversity, and instructional proficiency. The school can also foster teacher leadership through the determined themes - initiative and independence, partnership engagement and teamwork, and positive school environment. This study can also be a subject for further research to analyse if there is a significant difference between these types of leadership behaviour, and use the same method and instrument but is implemented in a larger population.
\end{abstract}

Keywords: proficient teacher, teacher-leader, case study, public secondary school, mixed method paradigm

\section{INTRODUCTION}

One of the challenges of any newly established schools is to how each school-based programs and projects and of those mandated by the top management will be assigned effectively and efficiently with the limited number of proficient teachers and of the absence of Highly Proficient Teachers and Department Heads. It has been also a dilemma that aside from their job in curriculum and instruction, there are also ancillary works which do not match with the personal and professional characteristics and goals of the proficient teachers which yield undesirable outcomes. It is also found out that the process of becoming a teacherleader from being an ordinary classroom teacher is gradual and recursive that occurs over a period of months or even years because most of the teachers do not set out to be leaders (Hunzicker, 2017). With this, the case will focus on the teachers of Manlilisid National High School (MNHS), Javier II District, Divison of Leyte, which is located at the Southern part of Javier, Leyte, since the school is built a near decade ago and almost all the teachers in this institution are proficient teachers. This examines and determines the strengths and weaknesses in leadership aspects of the proficient teachers and the school.

Also, this case study research is highly needed in the current limitation of a combined interpretation of quantitative and qualitative data regarding the emergence of proficient teachers as teacher-leaders. Most of the case study researches recently primarily focus only 
on the qualitative aspects of the study. Also, some previous researches implement the problem in the primary schools and in the graduate school internationally. But with the present study we can look into how proficient teachers in a public secondary school are characterized as teacher-leaders within the Philippine setting and through the use of a mixed method paradigm.

Accordingly, this study sought to provide data from the proficient teachers of Manlilisid National High School in terms of their leadership characteristics and cross-check with that of the school to determine the capability of the school to support and foster teacher leadership and to address the educational leadership problems.

\section{Statement of the Problem}

This study aimed to explore and characterize proficient teachers as teacher-leaders at Manlilisid National High School, Javier II District, Leyte Division. Specifically, the study sought answer to the following questions:

1. What are the characteristics of the proficient teachers as teacher-leaders at Manlilisid National High School?

2. How can Manlilisid National High School foster teacher leadership?

\section{Definition of Terms} provided:

For a better comprehension on this study, the following definition of terms are

Proficient Teachers - those teachers who are categorized as Teacher I, Teacher II or Teacher III, and are taking permanent position either in Junior High School or Senior High School.

Teacher-Leaders - those proficient teachers who exhibit leadership skills and participate in school activities as a coordinator or a chairperson, aside from delivering the curriculum and instruction.

\section{REVIEW OF RELATED LITERATURE}

In this section, it focuses on the reading, reviewing, and integrating the various literature in the current study. It discusses the meaning of teacher leadership, the previous studies of teacher leadership, and distributed leadership.

The process of progression of "just a teacher" to become "teacher leader" is gradual and recursive that happens over a period of months or even years. The progression also is not steady and linear because most of the teachers do not set out to be leaders (Hunzicker, 2017; Moore, Latimer, \& Villate, 2016). However, there is really a need to take on leadership roles for personal and professional growth and to improve schools (Moore, Latimer, \& Villate, 2016).

\section{Meaning of Teacher Leadership}

The idea of teacher leadership as a powerful force in school reform is not new (Moore, Latimer, \& Villate, 2016). In a literature review conducted by Norwani, Yusof, Mansor, \& Daud (2016) to understand the leadership practices among teachers in Malaysian 
schools, they showed that although there are various types of leadership models, one of the common elements exhibited by the models is that teachers are leaders of educational organizations with the attitude and capability to provide ideas, innovations and manage change through evidence-based practices. In addition, teachers foster continual outreach programmes with diverse communities and capitalize on opportunities through networking to provide a sense of belonging and responsibility to the local and global communities. They also established indicators in developing teacher leadership guiding principles including (a) curriculum and instruction, (b) teacher leadership, (c) administration, (d) collaboration/sharing expertise \& mentoring, (e) practice professional learning for continuous improvement, (f) professional networking, and (g) supreme-practitioner/reference leader.

Moreover, Wills (2015) also defined that teacher-leaders are those excellent educators who collaborate with their colleagues to improve teaching and participate in school wide decision-making process. In this regard, a key element of teacher leadership is the ability to lead and collaborate with colleagues. Kiral (2020), on the other hand, also described that those who have achieved excellence and who demonstrate leadership behaviours have a better future that can be realized through being aware of their competences and expectations.

In the broader concept of educational change, three key dimensions of teacher leadership are needed to be considered. First, the importance of teacher leadership as influence. Second, the idea of teacher leadership as action going beyond their formally assigned classroom roles to share practice and initiate changes. Finally, developing pedagogical excellence within their classroom and beyond to influence the practice of others (Harris \& Jones, 2019).

\section{Previous Teacher Leadership Studies}

In the case study conducted by Wills (2015), the case took place in a suburban elementary school located in an urban district in the Northeast United States, in which 34 teachers from grades $\mathrm{K}$ to 6 were studied. In the study, it was found out that instructional proficiency as a leadership behaviour has the highest frequency. Also, the study captured the instructional beliefs of the teacher leaders, as well as the activities of the school that teachers may engage in. With this, it was found out that the common philosophy of the teachers is on comprehensive education which refers to general education for life, and the activities made by the school in which the teachers often engaged are in developmental focus and positive environment.

Another qualitative study was conducted by Medina (2014) in an elementary school in which the purpose is to explain teacher leadership in public education and identify the principles of effective teacher leadership and the barrier that inhibit teacher leader participation in public school reform efforts. These principles involved contextualized leadership; relationships among roles; essential diversity; interaction of motivation, autonomy, and participation; sustainable leadership; and systems thinking. However, Sebastian, Allensworth, \& Huang (2016) in their study at an elementary school revealed that effective teacher leadership is not independent of principal leadership. The central assumption in the conceptual and analytical model of their study was that principal leadership influences teacher influence. Also, they added that teacher leadership produces strong school climate which appears to be the key mediating mechanism through which it is related to student achievement and principals influence.

In addition, those studies primarily focused on the primary level of education as the scope of the study. Moore, Latimer, \& Villate (2016), on the other hand, identified themes that emerge from online master's level teacher leadership program as part of the qualitative 
phenomenologial research projects focusing on the participant's perspectives of professional growth in knowledge, skills, and dispositions as a potential leader. Some of the themes that emerged from the study were confidence and well-being as a teacher, better use of research and assessment, and deeper understanding of relationship of teacher to school and community.

Thus, the abovementioned studies recently focused only on the qualitative aspects. Also, some of them implemented the problem in the primary schools and in the graduate school internationally. But with the present study we can explore how proficient teachers in a public secondary school are characterized as teacher-leaders within the Philippine setting using a mixed method paradigm, and compare the results with those recent studies above.

\section{Distributed Leadership}

A type of leadership that places decision-making power in the hands of those who are vested in the education process, namely teachers is called distributed leadership (Gronn, 2002; Spillane, Halverson, \& Diamond, 2001, 2004; Wills, 2015). In this regard, Medina (2014) in his dissertation was able to come up with a distributed leadership framework. It presented that the teacher leadership practice activity is anchored to distributed leadership. Specifically, the distributed leadership will be assessed in terms of leadership types, expertise, roles, influence, situation, and practice.

\section{METHODOLOGY}

In this section, it discusses the research design, the case, the data collection methods, and the data analysis methods.

\section{Research Design}

This study employed descriptive case study research as its research design through mixed-method investigative paradigm. According to Creswell (2013), mixed method is a research approach in which researchers collect, analyse, and integrate both quantitative and qualitative data in a single study or in a sustained long-term program of inquiry to address their research questions.

\section{The Case}

This study was conducted in Javier II District, Divison of Leyte at Manlilisid National High School (MNHS), which is located at the Southern part of Javier, Leyte, since the school is built a near decade ago and almost all the teachers in this institution are proficient teachers. This examines and determines the strengths and weaknesses in leadership aspects of the proficient teachers and the school.

In addition, the place was chosen as the participants were available and the ease of accessibility of the place for the researcher was highly considered. The goal of this study aimed to explore and characterize proficient teachers as teacher-leaders in this public secondary school - their strengths and weaknesses to become teacher-leaders, and the capability of the school to support teacher leadership.

This study used simple random sampling as its sampling procedure within the population of proficient teachers. The thirteen proficient teachers were asked to participate in 
a survey. Based on the results of the survey, some of the proficient teachers were requested to participate in individual interviews.

Specifically, there are thirteen (13) proficient teachers who participated and completed the answering of the survey-questionnaire, that is, eleven (11) Teacher I, and two (2) Teacher II, while three (3) proficient teachers from that group were interviewed.

\section{Data Collection Methods}

The data for this case study were collected using survey-questionnaire, and semistructured interview. The survey-questionnaire used in this study was taken and was also utilized in the study of Wills (2015) - the Teacher Leadership Self-Assessment (TLSA) authored by Katzenmeyer and Katzenmeyer (2004). The reliability and validity of the research instrument was already checked.

Table 1 below shows the research questions and their corresponding data collection procedure and instrument.

Table 1

The Research Questions and the Corresponding Research Instruments

\begin{tabular}{|l|c|c|}
\hline \multicolumn{1}{|c|}{ Research Questions } & Method of Collection & Instrument \\
\hline $\begin{array}{l}\text { What are the characteristics of the } \\
\text { proficient teachers as teacher- } \\
\text { leaders at Manlilisid National } \\
\text { High School? }\end{array}$ & Survey & $\begin{array}{c}\text { Teacher Leadership Self- } \\
\text { Assessment }\end{array}$ \\
\hline $\begin{array}{l}\text { How can Manlilisid National High } \\
\text { School foster teacher leadership? }\end{array}$ & Semi-structured interview & $\begin{array}{c}\text { Researcher-developed } \\
\text { interview questions }\end{array}$ \\
\hline
\end{tabular}

To characterize the proficient teachers as teacher-leaders at Manlilisid National High School, survey-questionnaire about self-assessment on teacher leadership was given to randomly selected teacher-participants. Those participants who got high overall scores on this survey were selected and subjected for a one-on-one interview to better understand the complexities of teacher leadership in this institution, how the school can improve teacher collaboration, how the school can improve active participation among teachers in making important decisions, and what the school can do to improve open communication between the faculty and the administration.

Specifically, this study utilized the Teacher Leadership Self-Assessment (TLSA) as the main survey questionnaire created by Katzenmeyer and Katzenmeyer (2004) and also used in the study of Wills (2015). According to Wills (2015), this 42-item survey is a selfreflection instrument, in the form of Likert scale tool (1-never, 2-rarely, 3-sometimes, 4often, and 5-always) for teachers to understand the frequency of engagement of various leadership behaviors. These seven types of leadership behaviors include (a) self-awareness, (b) leading change, (c) communication, (d) diversity, (e) instructional proficiency and leadership, (f) continuous improvement, and (g) self-organization.

For triangulation purposes, a semi-structured interview was also done to understand fully the complexities of the characteristics of the proficient teachers as teacher-leaders, and to explain clearly how the school fosters and develops leadership skills among the proficient teachers.

The researcher has followed certain procedures in conducting the study. That is, (1) secure permit to conduct the study. The permit to conduct the study was requested field to the 
office of the school principal. (2) The researcher administered the survey-questionnaire. The teacher-participants were also informed about their rights, and the nature of the study. The participants were given minutes to answer the survey questionnaire. After that, it was collected. (3) Lastly, a semi-structured interview was done to proficient teachers who got a high overall rating in the survey.

\section{Data Analysis}

The quantitative data obtained through the use of survey questionnaire are analyzed using descriptive statistics for the first research question about what are characteristics of the proficient teachers as teacher-leaders.

For descriptive statistics, all information attained from the utilization of the survey questionnaire are organized and presented in the form of tables to provide a brief summary of the samples and the measures done in a particular study, including the frequency, percentages and measures of central tendency in every type of leadership behavior.

For correctness and accuracy, the descriptive statistics is processed and computed using the Microsoft Excel and the Jeffreys' Amazing Statistical Program (JASP).

Finally, the results gathered from the oral interviews on how can the school foster teacher leadership are carefully treated and interpreted through thematic analysis by identifying patterns or themes within qualitative data. By using it, it is possible to link the various concepts and opinions of teacher-participants and compare them with the data gathered from the survey-questionnaire.

\section{RESULTS AND DISCUSSIONS}

In this section, the data gathered has been determined and tabulated using the Microsoft Excel, and processed using the Jeffreys' Amazing Statistical Program (JASP) for descriptive statistics. Also, the data gathered from the oral interviews conducted are hereby interpreted and presented through thematic analysis.

\section{Characteristics of the Proficient Teacher as Teacher-Leaders}

Table 2 shows the demographic characteristics of the teacher-participants at Manlilisid National High School. Out of thirteen proficient teachers, eleven, or $84.615 \%$ of the teachers have a permanent position of Teacher I and two, or $15.385 \%$ of the teachers have permanent position of Teacher II. This suggests that there are more teachers who are not yet reclassified or promoted to a higher position in the school.

Table 2

Demographic Characteristics of Teacher-Participants at Manlilisid National High School

\begin{tabular}{|l|l|l|l|}
\hline \multicolumn{1}{|c|}{ Criteria } & \multicolumn{1}{|c|}{ Specification } & \multicolumn{1}{c|}{ Frequency } & \multicolumn{1}{c|}{ Percent } \\
\hline Designation & Teacher 1 & 11 & 84.615 \\
\cline { 2 - 4 } & Teacher 2 & 2 & 15.385 \\
\hline Years in Teaching & 3 to 5 years & 13 & 100 \\
\hline $\begin{array}{l}\text { Educational } \\
\text { Attainment }\end{array}$ & Bachelor's Degree & 6 & 46.154 \\
\cline { 2 - 4 } & $\begin{array}{l}\text { Earned Units, Master's } \\
\text { Degree }\end{array}$ & 5 & 38.462 \\
\cline { 2 - 4 } & Master's Degree & 1 & 7.692 \\
\hline
\end{tabular}




\begin{tabular}{|l|l|l|}
\hline $\begin{array}{l}\text { Earned Units, Doctorate } \\
\text { Degree }\end{array}$ & 1 & 7.692 \\
\hline Doctorate Degree & 0 & 0 \\
\hline
\end{tabular}

In addition, all of the participants are teachers with the average number of years of experience which ranges from 3 to 5 years. This indicates that these teachers are not new in the service and they are already oriented with the duties, responsibilities and other related works of being a public school teacher. In terms of educational attainment, six, or $46.154 \%$ teachers have bachelor's degree, five, or $38.462 \%$ teachers have earned units in master's degree, one, or $7.692 \%$ teacher has master's degree, another one, or $7.692 \%$ teacher has earned units in doctorate degree, and no teacher has doctorate degree. This shows that most of these proficient teachers are pursuing or have pursued their graduate studies either in master's or doctorate degree.

Table 3 presents the comparison between the self-assessment scores of each type of leadership behaviour. As presented in the table of descriptive statistics, the mean scores in self-assessment of the proficient teachers in self-awareness, leading change, communication, diversity, instructional proficiency, continuous improvement, and self-organization are $25.231,22.846,24.308,25.077,24.769,23.615$, and 24.385, respectively.

Table 3

Comparison of the Self-Assessment Scores of Teacher Leadership Behaviour Survey

\begin{tabular}{lrrrrrrr}
\hline & Self-Awareness & Leading Change & Comunication & Diversity & Instructional Proficiency & Continuous Improvement & Self-Organization \\
\hline Valid & 13 & 13 & 13 & 13 & 13 & 13 & 13 \\
Missing & 0 & 0 & 0 & 0 & 0 & 0 & 0 \\
Mean & 25.231 & 22.846 & 24.308 & 25.077 & 24.769 & 23.615 & 24.385 \\
Std. Deviation & 2.088 & 2.035 & 2.780 & 2.100 & 1.878 & 2.785 & 3.124 \\
Shapiro-Wilk & 0.966 & 0.884 & 0.959 & 0.904 & 0.974 & 0.965 & 0.878 \\
P-value of Shapiro-Wilk & 0.849 & 0.081 & 0.731 & 0.153 & 0.938 & 0.824 & 0.068 \\
Minimum & 22.000 & 20.000 & 20.000 & 21.000 & 21.000 & 18.000 & 20.000 \\
Maximum & 29.000 & 26.000 & 29.000 & 30.000 & 28.000 & 28.000 & 30.000 \\
\hline
\end{tabular}

Based on these statistics, self-awareness $(\mathrm{M}=25.231, \mathrm{SD}=2.088)$, diversity $(\mathrm{M}=25.077, \mathrm{SD}=2.1)$, and instructional proficiency $(\mathrm{M}=24.769, \mathrm{SD}=1.878)$ have higher scores than the other types of leadership behaviour. This means that the proficient teachers have the potentials and strengths in these areas.

Table 4, on the other hand, focuses on the results of the self-assessment scores in the different indicators of self-awareness as one of the types of leadership behaviour. As can be seen in the table of descriptive statistics, the median scores in the self-awareness by the teacher-participants in each one of the six statements are 4, 4, 5, 4, 4, and 4, respectively. Based on these statistics, the third statement has the highest median score among them.

Table 4

Results of the Self-Assessment Scores in Self-Awareness as Type of Leadership Behaviour

\begin{tabular}{lrrrrrr}
\hline & S1 & S2 & S3 & S4 & S5 & \multicolumn{1}{c}{ S6 } \\
\hline Valid & 13 & 13 & 13 & 13 & 13 & 13 \\
Missing & 0 & 0 & 0 & 0 & 0 & 0 \\
Median & 4.000 & 4.000 & 5.000 & 4.000 & 4.000 & 4.000 \\
Shapiro-Wilk & 0.825 & 0.820 & 0.646 & 0.628 & 0.754 & 0.766 \\
P-value of Shapiro-Wilk & 0.014 & 0.012 & $<.001$ & $<.001$ & 0.002 & 0.003 \\
\hline
\end{tabular}


This further indicates that majority of the proficient teachers are always clear about what they believe about teaching and learning $(\mathrm{Mdn}=5)$. Often, they reflect on what they do well and how they can improve as classroom teacher $(\mathrm{Mdn}=4)$, they understand how their strengths and needs for development will impact their role as a leader in the school $(\mathrm{Mdn}=4)$, they act in ways that are congruent with their values and philosophy when dealing with students and colleagues $(M d n=4)$, they seek feedback on how they might improve in their work setting $(\mathrm{Mdn}=4)$, and at work they behave in ways that are ethical and meet expectations for a high level of professional performance $(\mathrm{Mdn}=4)$.

Table 5 shows the results of the self-assessment scores of the teacher-participants in the leading change as one of the types of leadership behaviours. As presented in the table of descriptive statistics, the median scores of the six statements for this leadership behavior are 4, 3, 4, 4, 4, and 4, respectively. Based on these data, the second statement has the lowest median score, while the rest of the statements have the same median scores.

Table 5

Results of the Self-Assessment Scores in Leading Change as Type of Leadership Behaviour

\begin{tabular}{lrrrrrr}
\hline & L1 & L2 & L3 & L4 & L5 & \multicolumn{1}{c}{ L6 } \\
\hline Valid & 13 & 13 & 13 & 13 & 13 & 13 \\
Missing & 0 & 0 & 0 & 0 & 0 & 0 \\
Median & 4.000 & 3.000 & 4.000 & 4.000 & 4.000 & 4.000 \\
Shapiro-Wilk & 0.650 & 0.790 & 0.709 & 0.809 & 0.675 & 0.675 \\
P-value of Shapiro-Wilk & $<.001$ & 0.005 & $<.001$ & 0.009 & $<.001$ & $<.001$ \\
\hline
\end{tabular}

This further indicates that the proficient teachers are often inviting their colleagues toward the accomplishment of the vision and mission of the school $(\mathrm{Mdn}=4)$, involving colleagues when planning for change $(\mathrm{Mdn}=4)$, understanding the importance of school and district culture to improving student outcomes $(M d n=4)$, working toward the improvement of culture of the school $(\mathrm{Mdn}=4)$, and willing to spend time and effort building a team to improve the school $(\mathrm{Mdn}=4)$. However, the teacher-participants are just sometimes leading the others in accomplishing tasks $(\mathrm{Mdn}=3)$.

Table 6 below presents the results of the self-assessment scores of the proficient teachers in communication. As shown in the table of descriptive statistics, all of the statements as indicators for this type of leadership behaviour have the same median scores with a value of 4 .

Table 6

Results of the Self-Assessment Scores in Communication as Type of Leadership Behaviour

\begin{tabular}{lrrrrrr}
\hline & C1 & C2 & C3 & C4 & C5 & C6 \\
\hline Valid & 13 & 13 & 13 & 13 & 13 & 13 \\
Missing & 0 & 0 & 0 & 0 & 0 & 0 \\
Median & 4.000 & 4.000 & 4.000 & 4.000 & 4.000 & 4.000 \\
Shapiro-Wilk & 0.778 & 0.812 & 0.733 & 0.825 & 0.867 & 0.819 \\
P-value of Shapiro-Wilk & 0.004 & 0.010 & 0.001 & 0.014 & 0.048 & 0.012 \\
\hline
\end{tabular}

Generally, this means that often the proficient teachers listen carefully to others $(M d n=4)$, adjust their presentations to others $(M d n=4)$, seek perspectives of others and reflect other's thoughts and feelings with accuracy $(\mathrm{Mdn}=4)$, keep the group members on-task and on-time when facilitating small groups $(\mathrm{Mdn}=4)$, able to get almost everyone to participate 
when leading meetings $(\mathrm{Mdn}=4)$, and use electronic technology effectively to communicate with individuals and groups $(\mathrm{Mdn}=4)$.

Table 7 talks about the results of the self-assessment scores of the teacher-participants in diversity. As seen below in the table of descriptive statistics, the median scores of each six statements for this type of leadership behaviour are 4, 5, 4, 4, 4, and 4, respectively. The value of the median of the second statement is the highest among the other indicators.

Table 7

Results of the Self-Assessment Scores in Diversity as Type of Leadership Behaviour

\begin{tabular}{lrrrrrr}
\hline & D1 & D2 & D3 & D4 & D5 & D6 \\
\hline Valid & 13 & 13 & 13 & 13 & 13 & 13 \\
Missing & 0 & 0 & 0 & 0 & 0 & 0 \\
Median & 4.000 & 5.000 & 4.000 & 4.000 & 4.000 & 4.000 \\
Shapiro-Wilk & 0.795 & 0.628 & 0.778 & 0.778 & 0.675 & 0.592 \\
P-value of Shapiro-Wilk & 0.006 & $<.001$ & 0.004 & 0.004 & $<.001$ & $<.001$ \\
\hline
\end{tabular}

This further means that the proficient teachers always respect the values and beliefs that may be different from them $(\mathrm{Mdn}=5)$. On the other hand, the teachers just often understand the different point of view may be based on an individual's culture, religion, race or socioeconomic status (Mdn=4), enjoy working with diverse groups of colleagues at school $(\mathrm{Mdn}=4)$, work effectively with non-educators and person with special interests $(\mathrm{Mdn}=4)$, make special efforts to understand the beliefs and values of others $(\mathrm{Mdn}=4)$, and willing to share their beliefs and even when they are different from the beliefs of others $(\mathrm{Mdn}=4)$.

Table 8 presents the self-assessment scores of each statements of the instructional proficiency as type of leadership behaviour. As can be seen in the table of descriptive statistics, the median scores of the six statements are 4, 3, 4, 4, 4, and 4, respectively. This means that all of the five statements have the same median with the value of 4 , except for the second statement with the value of 3 .

Table 8

Results of the Self-Assessment Scores in Instructional Proficiency as Type of Leadership Behaviour

\begin{tabular}{lrrrrrr}
\hline & IP1 & \multicolumn{1}{c}{ IP2 } & IP3 & IP4 & IP5 & IP6 \\
\hline Valid & 13 & 13 & 13 & 13 & 13 & 13 \\
Missing & 0 & 0 & 0 & 0 & 0 & 0 \\
Median & 4.000 & 3.000 & 4.000 & 4.000 & 4.000 & 4.000 \\
Shapiro-Wilk & 0.592 & 0.628 & 0.778 & 0.675 & 0.646 & 0.628 \\
P-value of Shapiro-Wilk & $<.001$ & $<.001$ & 0.004 & $<.001$ & $<.001$ & $<.001$ \\
\hline
\end{tabular}

This further suggests that the teacher-participants often promote positive environment in the classroom $(M d n=4)$, persist to assure the success of all students ( $M d n=4)$, have a reputation for being competent in the classroom $(\mathrm{Mdn}=4)$, are approachable and open to sharing with their colleagues $(\mathrm{Mdn}=4)$, and act with integrity and fairness when working with students or adults $(\mathrm{Mdn}=4)$. However, they only sometimes use research-based instructional practices $(\mathrm{Mdn}=3)$. 
Table 9, at this point, shows the self-assessment scores of the teacher-participants in continuous improvement. As presented in the table of descriptive statistics, the median scores of all the six statements are the same with the value of 4 .

Table 9

Results of the Self-Assessment Scores in Continuous Improvement as Type of Leadership Behaviour

\begin{tabular}{lrrrrrr}
\hline & $\mathrm{Cl}$ & $\mathrm{Cl} 2$ & $\mathrm{Cl}$ & $\mathrm{Cl} 4$ & $\mathrm{Cl} 5$ & $\mathrm{Cl} 6$ \\
\hline Valid & 13 & 13 & 13 & 13 & 13 & 13 \\
Missing & 0 & 0 & 0 & 0 & 0 & 0 \\
Median & 4.000 & 4.000 & 4.000 & 4.000 & 4.000 & 4.000 \\
Shapiro-Wilk & 0.795 & 0.754 & 0.772 & 0.811 & 0.811 & 0.675 \\
P-value of Shapiro-Wilk & 0.006 & 0.002 & 0.003 & 0.009 & 0.009 & $<.001$ \\
\hline
\end{tabular}

In this case, majority of the proficient teachers often seek out all pertinent information from many sources before making a decision or taking action $(\mathrm{Mdn}=4)$, set goals and monitor progress towards meeting them $(\mathrm{Mdn}=4)$, analyse and use assessment information when planning $(M d n=4)$, participate in professional development and learning $(M d n=4)$, are proactive in identifying problems and working to solve them $(\mathrm{Mdn}=4)$, and work side-by-side with colleagues, parents and/or others to make improvements in the school or district $(\mathrm{Mdn}=4)$.

Table 10, on the other hand, focuses on the self-assessment scores of the teacherparticipants in relation to self-organization. As shown in the data, all of the six statements of this type of leadership behaviour have also the same median scores with a value of 4 .

Table 10

Results of the Self-Assessment Scores in Self-Organization as Type of Leadership Behaviour

\begin{tabular}{lrrrrrr}
\hline & SO1 & SO2 & SO3 & SO4 & SO5 & SO6 \\
\hline Valid & 13 & 13 & 13 & 13 & 13 & 13 \\
Missing & 0 & 0 & 0 & 0 & 0 & 0 \\
Median & 4.000 & 4.000 & 4.000 & 4.000 & 4.000 & 4.000 \\
Shapiro-Wilk & 0.733 & 0.809 & 0.795 & 0.820 & 0.766 & 0.733 \\
P-value of Shapiro-Wilk & 0.001 & 0.009 & 0.006 & 0.012 & 0.003 & 0.001 \\
\hline
\end{tabular}

Based on these statistics, it further indicates that the proficient-teachers often plan and schedule thoroughly so that they can accomplish tasks and goals ( $M d n=4)$, exhibit selfconfidence when under stress or in difficult situations $(M d n=4)$, work effectively as a team member $(M d n=4)$, show initiative and exhibit the energy needed to follow through to get desired results $(\mathrm{Mdn}=4)$, prioritize so that they can assure there is time for important tasks $(\mathrm{Mdn}=4)$, and create a satisfactory balance between professional and personal aspects in their lives $(\mathrm{Mdn}=4)$.

Table 11 summarizes the strengths and weaknesses of the proficient teachers as teacher-leaders based on the tables of descriptive statistics on how frequent the statements of the types of leadership behaviours are observed. The characteristics listed in strengths are those that are "ALWAYS" engaged in, while the characteristics listed in weaknesses are those that are "SOMETIMES" engaged in. The rest of the statements not listed are "OFTEN" done. 
Table 11

Strengths and Weaknesses of the Proficient Teachers Based on the Types of Leadership Behaviour

\begin{tabular}{|l|l|l|}
\hline \multicolumn{1}{|c|}{$\begin{array}{c}\text { Type of Leadership } \\
\text { Behaviour }\end{array}$} & \multicolumn{1}{|c|}{$\begin{array}{c}\text { Strengths } \\
\text { (Always Engaged) }\end{array}$} & $\begin{array}{c}\text { Weaknesses } \\
\text { (Sometimes Engaged) }\end{array}$ \\
\hline Self-Awareness & $\begin{array}{l}\text { I am clear about what I believe } \\
\text { about teaching and learning. }\end{array}$ & $\begin{array}{l}\text { I lead others in accomplishing } \\
\text { tasks. }\end{array}$ \\
\hline Leading Change & $\begin{array}{l}\text { I respect values and beliefs that } \\
\text { may be different from mine. }\end{array}$ & \\
\hline Communication & & $\begin{array}{l}\text { I use research-based } \\
\text { instructional practices. }\end{array}$ \\
\hline $\begin{array}{l}\text { Diversity } \\
\text { Proficiency }\end{array}$ & & \\
\hline $\begin{array}{l}\text { Continuous } \\
\text { Improvement }\end{array}$ & & \\
\hline Self-Organization & & \\
\hline
\end{tabular}

As presented on the table above, the strengths of the characteristics of the proficient teachers as teacher-leaders are identified in self-awareness and diversity which tell that the teacher-participants are always clear about what they believe about teaching and learning, and they respect the values and beliefs that may different from them, respectively. On the other hand, the weaknesses of the characteristics of the proficient teachers are found in leading change and instructional proficiency which cite that the teacher-participants only sometimes lead others in accomplishing tasks, and use research-based instructional practices, respectively.

\section{Teacher-Leadership as Fostered by the School}

\section{Personal and Professional Growth and Development}

One of the questions that is being asked to the proficient teachers being interviewed is to cite the aspects that the school should improve to foster teacher leadership, and what are those activities that the school is doing great. Common answers of the proficient teachers primarily suggest that the school should improve and try hard helping the new teachers be successful especially when these teachers are given coordinatorship of school-based programs or projects. School must also provide assistance, guidance or coaching if needed. Continually, school must actively support the professional development of faculty and staff to gain new knowledge and skills. Hence, the proficient teachers are expecting that the school and the staff are supportive of each other personally and professionally.

On the other hand, the school is often very dynamic in terms of sharing new ideas and strategies gained from each other.

\section{Motivation and Recognition}

It is apparent, according to the interviewee, that many of the teachers in the school can often take leadership roles. However, the school administration in the school should have confidence with these proficient teachers in terms of their professional skills and competence. Other teachers should also recognize the skills and competence of the proficient teacher who 
is trying to do leadership role. Also, the ideas and opinions of teachers should be valued and respected in the school so that they will feel involvement and importance. The interviewee also added that the school should celebrate each other's successes e.g. the successful work of teacher-leaders, the reclassification and/or promotion of teachers, and etc.

\section{Initiative and Independence}

The main responsibility of a teacher is to ensure that students are learning. The interviewee explained that they are often free to make judgments and take initiative for the improvement of their students in their role as a teacher. Also, she added that they often have the freedom to make choices about the use of time and resources, know how to bend the rules if necessary to help the students learn, have input to develop a vision for the school and its future, and can be innovative if they choose to be. But with all of these, the school just sometimes supports the proficient teachers in making changes in their instructional strategies.

\section{Partnership Engagement and Teamwork}

In any organization, partnership and teamwork is a must to make the work effective and efficient. In this case, the interviewee agreed that the teachers in the school often observe one another's work with students. Also, other teachers have helped find the creative ways to deal with challenges faced during classes, and the conversations among them are focused on students. However, she explained that there are also activities that school is just sometimes doing, that is, teachers influence one another's teaching, teacher talks with other teachers about her teaching and the curriculum, and teachers and administrators work together to solve students' academic and behaviour problems.

\section{Decision-Making Process}

The administrator and the teachers should work hand in hand in the different educational processes. The involvement of teachers in the decision-making process for the betterment and future of the school is also an indicator of good management. However, the interviewee said that the participation of the proficient teachers in this activity is low and sometimes considered. It means that the school should let teachers have input to decision about school changes, have a say in what and how the things are done, share decisions how time is used and how the school is organized, and understand, use and reach the consensus process before making important decisions. Thus, the opinions and ideas of the proficient teachers should be sought by the administrator in the school.

\section{Open Communication}

Communication is an integral aspect of management. This is an area in which the interviewee has a similar perception and experiences when doing the decision-making process. She said that the opportunity in communication with the higher management and with the other teachers is low and sometimes made. With this, the school improve the system through staying aware of what is happening because teachers and administrator share ideas at work, and talking freely and openly about feelings, opinions, and concerns in productive ways such as dealing with ways to better serve the students and their families, and using faculty meeting time for discussions and problem solving. Importantly, the members of the institution should not blame each other when things go wrong, but talk about ways to do better the next time.

\section{Positive School Environment}


According to the interviewee, one of the things often done in the school in maintaining the positive school environment is to treat teachers as professionals at all times, to be respected by parents, students, and administrators, and to feel positive about the ways they are responding to the student's needs. However, there are instances that some of these expected activities are sometimes done including the general satisfaction with the work environment among teachers while working in partnership or as a team with the administrator.

\section{Comparative Discussions of Quantitative and Qualitative Data}

The quantitative data presented in the table of descriptive statistics revealed that selfawareness $(\mathrm{M}=25.231, \mathrm{SD}=2.088)$, diversity $(\mathrm{M}=25.077, \mathrm{SD}=2.1)$, and instructional proficiency $(\mathrm{M}=24.769, \mathrm{SD}=1.878)$ have higher self-assessment scores compared to leading change $(\mathrm{M}=22.846, \quad \mathrm{SD}=2.035)$, communication $(\mathrm{M}=24.308, \quad \mathrm{SD}=2.78)$, continuous improvement $(\mathrm{M}=23.615, \mathrm{SD}=2.785)$, and self-organization $(\mathrm{M}=24.385, \mathrm{SD}=3.124)$. The same findings also existed in the case study conducted by Wills (2015) which took place in a suburban elementary school and was found out that instructional proficiency as a leadership behaviour has the highest frequency.

The data of the current study is also supported in the analysis of each type of leadership behaviour that the strengths of the specific characteristics of the proficient teachers as teacher-leaders are identified in self-awareness and diversity which tell that the teacherparticipants are always clear about what they believe about teaching and learning $(\mathrm{Mdn}=5)$, and they respect the values and beliefs that may different from them ( $M d n=5)$, respectively. However, one of the weaknesses of the characteristics of the proficient teachers is found in instructional proficiency, although this type of leadership behaviour obtained one with the highest mean scores, which cite that the teacher-participants only sometimes use researchbased instructional practices $(\mathrm{Mdn}=3)$. Another weakness of the proficient teachers has appeared in leading change which tells that the teacher-participants only sometimes lead others in accomplishing tasks $(\mathrm{Mdn}=3)$. In general, the rest of the specific characteristics of each type of leadership behaviours are often done by the proficient teachers.

These identified strengths and weaknesses in the leadership behaviours of the proficient teachers as teacher leaders should be addressed by the school. The qualitative data obtained from the proficient teachers interviewed provide on how the school can foster teacher leadership. Based on the themes identified with many positive remarks from the interviewees, the school has the potentials of advancing the teacher-leaders through initiative and independence, partnership engagement and teamwork, and positive school environment.

In terms of initiative and independence, the proficient teachers as teacher-leaders will be given the opportunity to make judgments and take initiative for the improvement of their students in their role as a teacher, to have the freedom to make choices about the use of time and resources, to bend the rules if necessary to help the students learn, to have input to develop a vision for the school and its future, and to be innovative if they choose to be. This finding also conforms to the principles presented by Medina (2014) particularly interaction of motivation, autonomy, and participation.

Partnership engagement and teamwork can also be fostered by the school to maximize teacher leadership. The teachers in the school often observe one another's work with students. Also, other teachers have helped find the creative ways to deal with challenges faced during classes, and the conversations among them are focused on students. 
Above all, a positive school environment is needed in teacher leadership so that teachers are treated as professionals at all times, respected by parents, students, and administrators, and they are feeling positive about the ways they are responding to the student's needs. This positive environment is also evident in the work of Wills (2015) which obtained the highest rating along with developmental focus on the activities made by the school in which the teachers are often engaged.

The school must improve the other themes determined by the teacher-participants interviewed that require positive changes so that the characteristics and/or other types of leadership behaviours of the proficient teachers as teacher-leaders will also be fully developed. It is also advantageous to employ distributed leadership that places decisionmaking power and teacher leadership practice activity (Medina, 2014) in the hands of those who are vested in the education process, particularly teachers (Gronn, 2002; Spillane, Halverson, \& Diamond, 2001, 2004; Wills, 2015). In this case, the members of the institution will have shared vision and responsibility to the school, which will be assessed in terms of leadership types, expertise, roles, influence, situation, and practice (Medina, 2014) .

\section{CONCLUSION}

The characteristics of the proficient teachers as teacher-leaders in Manlilisid National High School are dominant in self-awareness, diversity, and instructional proficiency than the other types of leadership behaviour namely leading change, communication, continuous improvement, and self-organization. Specifically, the strength of the characteristics of the proficient teachers is traced in self-awareness and diversity. However, one of the identified weaknesses is in instructional proficiency and the other is in leading change.

The school can also foster teacher leadership through the following determined themes with many positive remarks from the proficient teachers: initiative and independence, partnership engagement and teamwork, and positive school environment.

In a general sense, it can be deduced that the school has already the activities often conducted, and these activities should be always done to satisfy the leadership behaviours of the proficient teachers as teacher-leaders frequently.

\section{RECOMMENDATIONS}

The following recommendations are derived from the findings and conclusions.

- With the identified characteristics of the proficient teachers in leadership behaviour, the school must establish a training program in which the teachers will have the opportunity to enhance their strengths and improve their weaknesses in doing leadership roles.

- Based on the themes determined by the proficient teachers, the administration must improve itself to the different activities that require constant conduct to foster effectively teacher leadership.

- This case study can also be a subject for further research. The author only does the descriptive statistics with the quantitative data of the types of leadership behaviour. The future researcher can also study the parameter of the population if there is a significant difference between these types of leadership behaviour. 
- To compare also the findings of this study, the future researcher can also use the same method and instrument but is implemented in a larger population taken from big schools in Leyte Division or in other divisions.

\section{References}

Creswell, J. (2013). Steps in Conducting a Scholarly Mixed Methods Study. DBER Speaker Series, 48.

Harris, A., \& Jones, M. (2019). Teacher Leadership and educational change. School Leadership \& Management, 39(2), 123-126. doi:10.1080/13632434.2019.1574964

Hunzicker, J. (2017). From Teacher to Teacher Leader: A Conceptual Model. International Journal of Teacher Leadership, 8(2), 1-27.

Kiral, E. (2020). Excellent Leadership Theory in Education. Journal of Educational Leadership and Policy Studies, 4(1), 1-30.

Medina, A. J. (2014). Elementary Teacher Leaders: Theory and Methodology of Development. Unpublished Dissertation, 1-241.

Moore, H. L., Latimer, R. M., \& Villate, V. M. (2016). The Essence of Teacher Leadership: A Phenomenological Inquiry of Professional Growth. International Journal of Teacher Leadership, 7(1), 1-16.

Norwani, N. M., Yusof, H., Mansor, M., \& Daud, W. M. (2016). Development of Teacher Leadership Guiding Principles in Preparing Teachers for the Future. International Journal of Academic Research in Business and Social Sciences, 6(12), 374-388. doi:10.6007/IJARBSS/v6-i12/2503

Sebastian, J., Allensworth, E., \& Huang, H. (2016). The Role of Teacher Leadership in How Principals Influence Classroom Instruction and Student Learning. American Journal of Education, 69-108.

Wills, A. (2015). A Case Study of Teacher Leadership at an Elementary School. Unpublished Certificate of Advanced Study Thesis, 1-107. 